\title{
Impact of IT Investment on Hospital Performance: A Longitudinal Data Analysis
}

\author{
Giridhar Reddy Bojja \\ Dakota State University \\ giridhar.bojja@trojans.dsu.edu
}

\author{
Jun Liu \\ Dakota State University \\ jun.liu@dsu.edu
}

\begin{abstract}
With the enormous investments in Information Technology (IT), the question of payoffs from IT has become increasingly important. In this study, we investigate the impact of IT investments on hospital performance. We consider both financial outcomes such as return on investment and non-financial outcomes such as quality of care. We used longitudinal data that include the IT investments and hospital performance measures collected from over 500 hospitals and conduct a panel data analysis. The results of our study provide evidence for a significant positive relationship between IT investments and hospital performance measures.
\end{abstract}

\section{Introduction}

Hospitals have been continually endeavoring to control costs while improving operational performance, patient outcomes, and healthcare quality. A notable spending item for all hospitals is the spending on Information Technology. Health Information Technology (HIT) spending is inclining upward and retains over $6 \%$ of total operating budgets for many hospitals in the US [21].

Reasons behind the higher IT spending in the healthcare industry are various, including a lower overall IT adoption rate in the early decade as well as impacts of federal policy decisions and advancements in buyer/payer-driven marketplace. Health Information Technology Economic and Clinical Health Act (HITECH) approved incentive payments through Medicare and Medicaid to hospitals when they implement the EHR to improve quality, performance, and safety while maintaining privacy and security. In 2004, President Bush established the National Coordinator (ONC) for Health Information Technology, which is entrusted with the advancement and execution of a key intend to manage the nationwide implementation of health information technology. In 2009, \$ 19 billion per year funding was allocated by the U.S government to help healthcare providers implement electronic health records (EHR).

Information technologies used in healthcare have the capacity to improve the quality and efficacy of healthcare providers. A recent government survey of more than 2,600 doctors in the US on the use of the Electronic health record (EHR) indicates that $82 \%$ of the doctors felt the use of the EHR improved quality of clinical decisions, $86 \%$ stated that it helps to reduce medical errors, and $85 \%$ stated that it helps to improve the quality of the care [38]. Well-planned investments in IT that meet the business mission requirements can have a positive impact on organizational performance, whereas poorly planned investments in IT can severely limit the overall performance of an organization. The goal of this study is to examine the impact of IT investments on hospital performance. More specifically, we use both the IT budget and the implementation of different HIT systems (including Electronic Medical Records (EMR), Decision Support Systems (DSS), Clinical Information Systems (CIS) and Human Resource Information Systems (HRIS)) as measures of IT investments in each hospital and investigate their impact on the performance of the hospital.

Our research is one of the first that use IT budget, a monetary measure of IT investments, to study the impact of IT investments on hospital performance. Most similar studies such as [4, 13, 14, 24, 30] used the availability of several specific HIT systems (such as EMR, DSS and CIS) as the only indicator of IT spending in a hospital, which could lead to misleading conclusions as IT investments encompass much more than the spending on the three or four types of HIT systems investigated in those studies, and implementing the HIT systems may cost differently for different hospitals. Such studies may also lose their significance over time as HIT systems have been deployed in more hospitals in recent years. As of 2015, more than $20 \%$ of hospitals in the United States have installed all major categories of these information systems. Investigating the impact of IT budget on 
hospital performance provides us a boarder view of the issue, since in addition to the costs for implementing the HIT systems, IT budget also includes costs incurred in operating and maintaining the systems, IT staff expenditure, IT service and support cost, etc. It also affords us a more fine-grained view since IT budget allows us to compare the hospitals that have deployed similar HIT systems. Moreover, while earlier research $[1,3,4,21,32,36]$ primarily focused on the impact of IT investments on hospital outcomes linked to healthcare quality, we analyze the impact of IT investments on both financial outcomes such as Return on Investment and non-financial outcomes such as quality of care, thus providing additional insights into relationship between IT investments and hospital performance. We conducted a longitudinal study, more specifically a fixed-effects panel data models using real data collected from over 500 hospitals to empirically assess the relationship between IT investments and hospital performance.

\section{Literature Review}

There are a few studies that have investigated the impact of IT investments on hospital performance, including $[4,13,14,24,30]$. Almost all of them quantified the effects of healthcare IT investments by counting the number of HIT systems such as Electronic Medical Records (EMR), Decision Support Systems (DSS), Clinical Information Systems (CIS) and Human Resource Information Systems (HRIS) implemented in the hospitals. As an example, in [14], the authors conducted a longitudinal study on 8 hospitals over 3 years and found that investments in IT have a significant impact on healthcare quality, but they only considered mortality as a quality indicator.

Significant research has investigated the impact of HIT on hospital performance. The paper [9] presents a systematic literature review of 257 studies on HIT impact on quality of care and found that clinical Information systems can help in improving the quality of care by reducing medical errors and improved processes. Among the various HIT systems, implementation of EMR is high on the list of priorities for hospitals, and it is viewed as a system that will substantially contribute to improving quality of healthcare, patient safety, and cost-effectiveness. There are different applications built within EMR. Computerized practitioner order entry (CPOE) requires doctors to follow strict standards to order or request drugs, test, and services to the patients. Applications such as patient portal and physician portal increase visibility of health information, facilitates direct communication between patients and care teams, and boost patient safety. The research including [3], [29], [18] found that use of computerized applications like EMR and computerized practitioner order entry (CPOE) will have a significant effect on improving the quality of care, improving administrative efficiency, and reducing costs. The authors of [29] and [26] accessed the relationship between EMR technologies and 17 different quality measures. They found that the use of EMR has led to significant improvements in pneumonia treatment in 3 out of 14 quality measures. The paper [34] also reported that the use of EHR will improve quality of care. The authors of [25] reported that the use of influenza vaccinations and pneumococcal vaccinations have increased from $47 \%$ to $67 \%$ and $19 \%$ to $41 \%$ respectively as a result of using computerized reminders as a part of CPOE systems.

Human resource information systems such as scheduling systems and personal management help managers and admins with effective planning and resource allocation such as nurses, doctors, and equipment. The study presented in [37] found that Human Resource Systems are associated with greater client satisfaction and financial outcomes of hospitals. The study shown in [11] found that the use of administrative systems has an impact on hospital performance in a long run while the use of clinical information systems has an impact on hospital performance in a short run.

Decision support systems such as Business Intelligence and Data Mining helps in finding the inefficiencies and suitable practices to improve quality of care and reduce costs. McKinsey estimates the use of data mining applications can save $\$ 300$ billion per year in U.S healthcare [28]. Premier Healthcare Alliance reported that they have been using DSS technologies to improve patient outcomes, quality of care. They reported $\$ 7$ billion reduction in spending by saving 29,000 lives [22]. The paper [7] posits that the use of computer-based Decision Support Systems such as financial systems provides improvements in many organizational tasks thereby improvements in return on investments.

However, there are also studies that have questioned the viability of HIT investment on hospital performance. In the study, including [12] and [35], the authors have shown an implementation of clinical decision support systems and EMR had minimal improvements in quality of care. The study [20] posits that greater investments in IT have been reported to increase in administrative costs, but they have not led to any improvement on the quality of care. The study [10] contends that high investment may not be effective as the advancement in IT is lacking and fails to produce outcomes for the money spent. These mixed 
responses raise concerns about the capability of IT spending to improve hospital performance.

The aim of our research is to access the relationship between Healthcare IT investments and their impact on hospital performance. Following the existing research, we also use the adoptions of the various of HIT systems as an important indicator of IT investments and investigate their impact on hospital performance. However, our research is significantly different from the existing research in that we assess the impact of the overall IT budget, while most of the existing research just consider the impact of the adoptions of various HIT systems. Moreover, while most existing research focuses on the impact of HIT on only quality of care measures, we also study its financial impact since HIT is a resource that enhances the value of other organizational resources and capabilities, and this enhancement may be measured as an increase in productivity or profitability of hospitals. Return on investment is a measure of profitability, and it is a measure of hospital performance [8].

\section{Theoretical Framework}

Figure 1 presents the theoretical framework of our study. The overarching goal of our research is to investigate the impact of IT investments on hospital performance. We consider two constructs related to hospital performance, including the IT budget and the implementation of HIT systems in the hospitals. Following existing research such as [4, 14, 27, 34, 41] we consider four major types of HIT systems including Electronic Medical Records (EMR), Decision Support Systems (DSS), Clinical Information Systems (CIS), and Human Resource Information Systems (HRIS). We conceptualize hospital performance as a multidimensional concept comprising of Return on Investments, a financial outcome, and non-financial outcomes, including quality of care and patient satisfaction.
HIT Investment

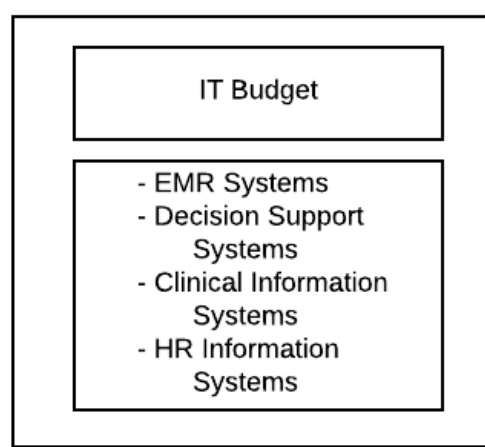

Hospital Performance

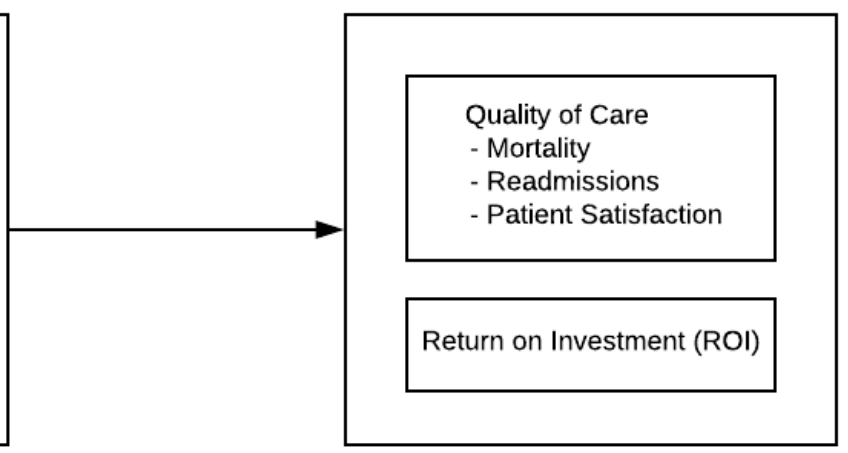

Figure 1. Theoretical framework

\section{Hypothesis Building}

In this research, we investigate the impact IT investment on 1) Quality of Care and 2) Return on Investment. World Health Organization defines Quality of Care as "the degree to which healthcare services provided to individuals and patients to improve desired health outcomes. So as to accomplish this, healthcare services must be effective, safe, impartial, and individuals focused [39] ." Quality of care is a significant factor in the discussion on the impact of HIT, mainly because HIT has a capability to improve quality of patient care and also the outcomes $[4,5,6]$. In addition to the commonly used quality of care measures including "mortality" used in $[1,3,4,5$, $13,14,18]$ and "readmission rates" used in $[3,4,18]$, we consider a critical quality of care measure that has been largely ignored in existing research, patient satisfaction. According to the survey reported in [40], keeping up consistency in the service quality and improving patient satisfaction are real inspirations behind IT spending increases.

We consider two constructs representing IT investments: IT budget and implementation of different HIT systems. An IT budget is a comprehensive financial plan for achieving the financial and operational goals of an organization. It is more the costs related to implementing different HIT systems and includes all IT-related operating expenses such as Total FTE, Computers, Cyberinfrastructure, etc. In the age of digital transformation, new innovative solutions for healthcare services show up practically every day. 
$27 \%$ of hospitals have seen more than $5 \%$ increments in their IT budget [40]. As the IT budget increases, we expect the payoff to rise.

We hence hypothesize:

Hypothesis 1: Increase in IT Budget leads to increase in quality of care.

More specifically, we propose:

Hypothesis 1.1: Increase in IT Budget leads to decrease in mortality.

Hypothesis 1.2: Increase in IT Budget leads to decrease in readmission rates.

Hypothesis 1.3: Increase in IT Budget leads to increase in patient satisfaction.

We also investigate the impact of the implementation of different HIT systems on the quality of care. We believe that HIT can improve decisionmaking abilities in various healthcare settings. Clinical Information systems are vital for delivering the best evidence-based care[16]. They play an important role to identify, store, process the data in a timely manner so that decision makers such as managers and nurses can take quick decisions [27]. For example, Emergency Department CIS can help predict patient flow and help minimize ED wait time, thereby helping reduce costs and increase patient satisfaction. EMR systems can enable doctors to utilize CPOE to contact patients to recommend medications. This helps to accelerate the transmission of prescriptions to the pharmacy and save patients time. The IT capability of CPOE also helps doctors report the bad interactions of the drugs, thereby reducing the adverse effect of drugs, which ultimately helps reduce mortality rates and reduce both inpatient and outpatient visits [2]. Implementation of Decision Support Systems (DSS) also plays a positive role in the healthcare. Interpretation of huge volume of patient data with learning based techniques enables physicians and nurses to quickly accumulate information and process it in different routes so as to assist with diagnosis and treatment choice [17]. For example, studies including [19, 23, 36] have used various DSS driven decision models to predict the occurrence of diabetes and heart attack. By identifying the early occurrence of diseases can help physicians take necessary actions to reduce the occurrence, thereby improving the quality of care. Human Resource Information Systems such as staff scheduling, personnel management, billing, etc. enable hospitals to optimize the allocation of the existing resources such as physicians, operating rooms, nurses, support staff, etc., thereby saving labor and increase the productivity [15]. Hence, we hypothesize:

Hypothesis 2: Implementation of HIT systems leads to increase in quality of care.
More specifically, we hypothesize:

Hypothesis 2.1: Implementation of Clinical Information Systems (CIS) leads to increase in quality of care.

Hypothesis 2.2: Implementation of Electronic Medical Records (EMR) leads to increase in quality of care.

Hypothesis 2.3: Implementation of Decision Support Systems (DSS) leads to increase in quality of care.

Hypothesis 2.4: Implementation of Human Resource Systems (HRS) leads to increase in quality of care.

Since quality of care is multidimensional that include mortality, readmission and patient satisfaction rates, we further hypothesize:

Hypothesis 2.1.1: Implementation of Clinical Information Systems (CIS) leads to decrease in mortality.

Hypothesis 2.1.2: Implementation of Clinical Information Systems (CIS) leads to decrease in readmission rates.

Hypothesis 2.1.3: Implementation of Clinical Information Systems (CIS) leads to increase in patient satisfaction.

Hypothesis 2.2.1: Implementation of Electronic Medical Records (EMR) leads to decrease in mortality. Hypothesis 2.2.2: Implementation of Electronic Medical Records (EMR) leads to decrease in readmission rates.

Hypothesis 2.2.3: Implementation of Electronic Medical Records (EMR) leads to increase in patient satisfaction.

Hypothesis 2.3.1: Implementation of Decision Support Systems (DSS) leads to decrease in mortality.

Hypothesis 2.3.2: Implementation of Decision Support Systems (DSS) leads to decrease in readmission rates. Hypothesis 2.3.3: Implementation of Decision Support Systems (DSS) leads to increase in patient satisfaction. Hypothesis 2.4.1: Implementation of Human Resource Systems (HRS) leads to decrease in mortality.

Hypothesis 2.4.2: Implementation of Human Resource Systems (HRS) leads to decrease in readmission rates. Hypothesis 2.4.3: Implementation of Human Resource Systems (HRS) leads to increase in patient satisfaction.

Next, we focus on the financial outcome of hospital IT investments with respect to Return on Investment. With the large investments made in Information technology to improve healthcare, ROI has become a question of interest. While the primary goal of any healthcare organization is to provide good care rather than seeking higher financial returns, the increasing costs of IT products and services make it necessary for healthcare organizations to gauge their ability to fund the IT investments and possible future investments to maintain their IT development [8, 32]. It is hence 
critical to investigate the impact of IT investment on the Return on Investment. We propose,

Hypotheses 3: Increase in IT Budget leads to increase in Return on Investment (ROI).

Next, we examine if the implementation of HIT systems will lead to greater ROI. EMR systems store patient data electronically, which eliminates a lot of paperwork and also eliminates the cost of assigning full-time employees to maintain the paperwork. The research conducted by [31] shows that the usage of EMR and Clinical Information Systems have shown an increase in revenue, operational efficiency and return on investment. Decision support systems that identify the patterns of ER usages and staff availability can help identify the inefficiencies and reduce the operational costs. Similarly, Human Resource Information systems can automate many processes such as allocating human and other recourses, posting jobs in various recruiting sites, and tracking applicants, thus restricting the use of FTEs and reducing the operational costs. We hence hypothesize:

Hypotheses 4: Implementation of HIT systems leads to increased ROI.

More specifically, we hypothesize:

Hypotheses 4.1: Implementation of Clinical Information Systems (CIS) leads to increased ROI.

Hypotheses 4.2: Implementation of Electronic Medical Records (EMR) leads to increased ROI.

Hypotheses 4.3: Implementation of Decision Support Systems (DSS) leads to increased ROI.

Hypotheses 4.4: Implementation of Human Resource Systems (HRS) leads to increased ROI.

\section{Empirical Study}

\subsection{Data}

Data was collected from three sources. We obtained IT Investments data from the HIMSS Analytics Database, primarily known as Dorenfest Integrated Healthcare Delivery Systems database. It provides detailed data on investments and usage of HIT among various hospitals in the U.S. Secondly, we obtained data on quality of care i.e. Mortality, Readmissions, and Patient Satisfaction from Medicare Hospital Compare Database. Lastly, we collected data on Case Mix Index, which is one of the control factors from the Center of Medicare and Medicaid Services (CMS). For the study purpose, we collected data of 4 years i.e. 2012-2015 from a panel of hospitals from all threedatabase and combined them using common identifier i.e. Medicare Number. We have initially collected data of more than 1500 hospitals, but only 531 hospitals were reported data for all the measures used in this study. So, the sample used in this study contains data from 531 hospitals. We are using unbalanced panel data set for this study as a set of hospitals were not observed in certain years.

\subsection{Variables}

Table 1 shows the independent variables, dependent variables and control variables in our study.

In our study, we used the IT budget as a measure of IT investments. The IT budget data of the hospitals in the sample were obtained from HIMSS Analytics Database. IT budget is the total amount of money budgeted by the IT department at the hospital. It is the IT department operating expense as a percent of total operating expense. This amount includes all HIT related operating expenses such as computers, software's, infrastructure and labor etc.

Table 1. Variables used in our study

\begin{tabular}{|c|c|c|}
\hline Variables & Description & Range \\
\hline \multicolumn{3}{|l|}{ Dependent Variables } \\
\hline Mortality & Death rate of patients. & $8.05-16.4$ \\
\hline Readmission & Readmission rate of patients & $16.10-26.15$ \\
\hline Patient Satisfaction & $\begin{array}{l}\text { Extent to which patients are happy with their healthcare, } \\
\text { both inside and outside of doctor's office. }\end{array}$ & $53.5-86.5$ \\
\hline Return on Investment (ROI) & Measure of profitability of the hospital. & $0.232-1.286$ \\
\hline \multicolumn{3}{|l|}{ Independent Variables } \\
\hline IT Budget & Dollars spent on HIT. & $0.006-0.301$ \\
\hline $\begin{array}{l}\text { Electronic Medical Records } \\
\text { Systems }\end{array}$ & $\begin{array}{l}\text { The extent of EMR systems implementation by each } \\
\text { hospital. }\end{array}$ & $0-1$ \\
\hline Decision Support Systems & The extent of DSS systems implementation by each & $0-1$ \\
\hline
\end{tabular}




\begin{tabular}{|l|l|l|}
\hline & hospital. & \\
\hline Clinical Information Systems & $\begin{array}{l}\text { The extent of CIS systems implementation by each } \\
\text { hospital. }\end{array}$ & -1 \\
\hline $\begin{array}{l}\text { Human Resource Information } \\
\text { Systems }\end{array}$ & $\begin{array}{l}\text { The extent of HRS systems implementation by each } \\
\text { hospital. }\end{array}$ & $0-1$ \\
\hline Control variables & Total number of beds. & $26-1764$ \\
\hline Hospital Size & Severity of patient disease case mix. & $1.008-2.314$ \\
\hline Case Mix Index &
\end{tabular}

We grouped HIT applications into four major HIT systems by drawing upon the previous studies such as [4] and [14] that classify HIT applications into four major categories including Electronic Medical Record (EMR), Decision Support Systems (DSS), Human Resource Information Systems(HRS), and Clinical Information Systems (CIS). Each of these four systems encompasses a number of applications, as given in the Appendix A.

The dependent variables in the study include quality of care measures and return on investment (ROI). The quality measures include Mortality, Readmission, and Patient Satisfaction. Mortality is percentage of number of deaths of patients from the total number of patients. For mortality, we provide a cumulative average score of the death rate of heart failure patients and death rate of pneumonia patients. Readmission is percentage of patients who were readmitted into the hospital from the total number of previously admitted patients, which was then calculated as a cumulative average of readmission rates of heart failure patients and that of pneumonia patients. Patient Satisfaction is percentage of patients who are satisfied with their healthcare, both inside and outside doctor's office, from the total number of patients. For patient satisfaction, we provide a cumulative average score of the patients who reported "yes, they would definitely recommend the hospital" and the number of those who reported that

Table 2. Percentage of quality measures for hospitals over the years

\begin{tabular}{|l|l|l|l|}
\hline Year & Mortality & Readmission & $\begin{array}{l}\text { Patient } \\
\text { Satisfaction }\end{array}$ \\
\hline 2015 & 11.37 & 19.39 & 75.84 \\
\hline 2014 & 11.75 & 20.10 & 75.49 \\
\hline 2013 & 11.96 & 20.23 & 75.33 \\
\hline 2012 & 11.90 & 21.19 & 74.75 \\
\hline
\end{tabular}

their doctors "Always' communicated well" in hospital surveys". We also consider the Return on Investment (ROI) as a financial overcome of IT investments. Return on Investment is a measure of profitability, and it tells us if the hospital has the ability to fund current operations and future investments [39]. We calculated ROI given a hospital as net patient revenue generated by the total operating expense of the hospital.

We used hospital size represented as number of beds in the hospital and Case Mix Index that represents the severity of patient disease case mix in the hospital as control variables, since hospital of different sizes may show different IT adoption behaviors, and CMI may affect the quality of healthcare due to differences in patient case severity across hospitals. We ignored some of the other variables such as location, type of hospitals and ownership status as they are timeinvariant. In our research, we used fixed-effect panel data analysis to control these time-invariant variables.

\subsection{Descriptive Statistics}

Table 2 shows overall rates of quality measures among the U.S hospitals in our sample from 20122015. We observe the mortality, readmission and patient satisfaction rates are increased steadily during the periods of the study.

Table 3 shows the descriptive statistics on the variables in hospitals of different size from 2012-2015. We observe that a larger hospital has less mortality rates than small hospitals. Readmission and Patient satisfaction rates are almost equal in hospitals of different size. We can observe that investments in HIT applications are smaller in a smaller hospital when compare to large hospitals. We also note that the return on investment (ROI) is larger in smaller hospitals than bigger hospitals.

Table 3. Variations in quality of care and IT investments by hospital size

\begin{tabular}{|c|c|c|c|c|c|c|c|c|c|}
\hline & \multicolumn{3}{|c|}{ Quality of Care (\%) } & \multicolumn{5}{|c|}{ HIT Investments (\%) } & Financial \\
\hline Hospital & Mort & Read & PS & DSS & $\mathrm{CIS}$ & HRS & EMR & IT & $\mathrm{ROI}$ \\
\hline
\end{tabular}




\begin{tabular}{|l|l|l|l|l|l|}
\hline Bed Size & & & & & \\
\hline $1-50$ & 12.5 & 20.7 & 76.8 & 62.0 & 55.2 \\
\hline $51-250$ & 12.0 & 20.5 & 74.5 & 72.1 & 70.0 \\
\hline$>250$ & 11.6 & 20.7 & 75.7 & 80.0 & 75.8 \\
\hline
\end{tabular}

\subsection{Model Specification}

The investment in IT can vary across organizations and can also vary in different time periods for the same hospital. The impact the IT investments may also vary across hospitals over different time periods. So, Cross- sectional set of hospitals combined with time-series data is ideal for examining the effect of IT investments on quality of care and return on investments. The research design that contains data over various time periods as well as various hospitals is also known as "panel data" in the econometrics. We employed a fixed-effect panel model that uses quality of care measures as the dependent variables and HIT investments as the independent variables. The fixed-effect model exploits the variation within- hospital across different time periods. The model specification is as follows.$$
\operatorname{Mort}_{i, t}=\alpha_{0}+\alpha_{1} I T_{-} \text {Budget }_{i, t}+
$$$$
\text { 1) } \alpha_{2} \text { Hosp_size }_{i, t}+\alpha_{3} \text { CMI I }_{i, t}+\varepsilon_{i, t}
$$$$
\operatorname{Read}_{i, t}=\beta_{0}+\beta_{1} I T_{-} \text {Budget }_{i, t}+
$$$$
\text { 2) } \beta_{2} \text { Hosp_size }_{i, t}+\beta_{3} \mathrm{CMI}_{i, t}+\varepsilon_{i, t}
$$$$
P S_{i, t}=\gamma_{0}+\gamma_{1} I T_{-} \text {Budget }_{i, t}+\gamma_{2} \text { Hosp_size }_{i, t}+
$$$$
\text { 3) } \gamma_{3} C M I_{i, t}+\varepsilon_{i, t}
$$$$
\text { ROI }_{i, t}=\delta_{0}+\delta_{1} I T_{-} \text {Budget }_{i, t}+
$$$$
\text { 4) } \delta_{2} \text { Hosp_size }_{i, t}+\delta_{3} \mathrm{CMI}_{i, t}+\varepsilon_{i, t}
$$$$
\text { Mort }_{i, t}=\alpha_{0}+\alpha_{1} \text { Clinical }_{i, t}+\alpha_{2} \text { EMR }_{i, t}+
$$$$
\alpha_{3} D_{S S} S_{i, t}+\alpha_{4} H R_{i, t}+\alpha_{5} \text { Hosp_size }_{i, t}+
$$$$
\text { 5) } \alpha_{6} C M I_{i, t}+\varepsilon_{i, t}
$$

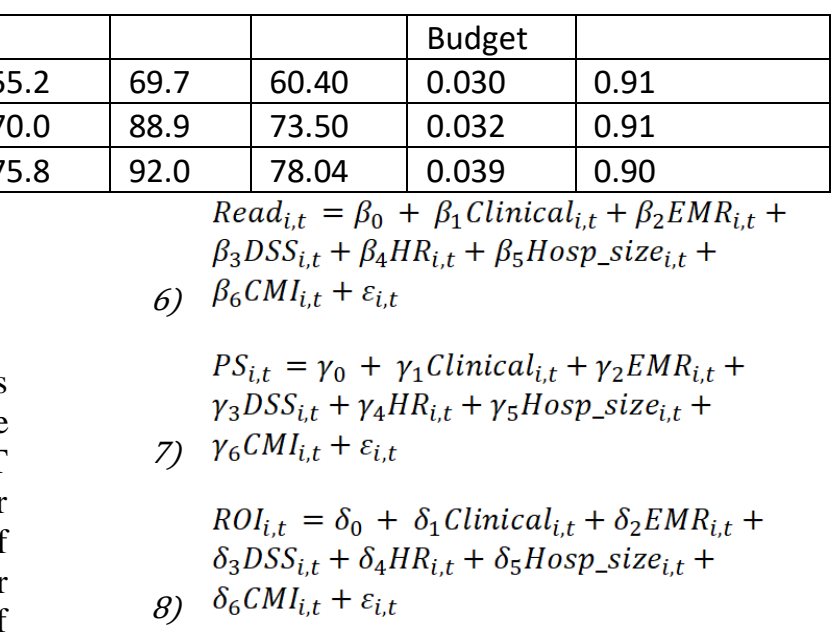

Where Mort $_{i, t}$ represents the quality score for mortality rates by hospital $i$ in year $t . \operatorname{Read}_{i, t}$ and $P S_{i, t}$ represent the readmission rates and patient satisfaction scores. $R O I_{i, t}$ represents Return on Investment score for hospital $i$ in year $t$. IT_Budget $t_{i, t}$ represents IT Budget for hospital $i$ in year $t$. Consistent with existing research $[4,13,14,18]$, we used hospital size and Case Mix Index (CMI) that represents the severity of patient disease case mix in a hospital as control variables that may influence the effect of IT investments on hospital performance. Hosp_size $i, t$ represents the size of a hospital in terms of the number beds in hospital $i$ in year $t . C M I_{i, t}$ represents the case mix index of a hospital $i$ in year $t$. We used unbalanced panel data to test our hypotheses. Using Variance inflation factors, we checked multi-collinearity, and results were in the acceptable threshold.

\section{Results}

Table 4 shows our panel data regression results.

Table 4. Fixed effects estimation on HIT investments on hospital performance

\begin{tabular}{|l|l|l|l|l|}
\hline & \multicolumn{3}{|c|}{ Dependent Variables } \\
\hline $\begin{array}{l}\text { Independent } \\
\text { Variables }\end{array}$ & Mortality & Readmission & Patient Satisfaction & ROI \\
\hline IT Budget & $31.98^{* *}$ & 13.15 & $78.94^{* *}$ & $1.669^{* * *}$ \\
\hline $\begin{array}{l}\text { Clinical Information } \\
\text { Systems }\end{array}$ & -0.208 & $-1.423^{* * *}$ & $1.627^{* *}$ & $0.005^{* *}$ \\
\hline EMR Systems & $-0.761^{* * *}$ & $-0.819^{* * *}$ & 0.040 & 0.006 \\
\hline $\begin{array}{l}\text { Decision Support } \\
\text { Systems }\end{array}$ & $-0.638^{* * *}$ & $-0.057^{*}$ & $1.852^{* *}$ & -0.015 \\
\hline
\end{tabular}




\begin{tabular}{|c|c|c|c|c|}
\hline $\begin{array}{l}\text { Human } \quad \text { Resource } \\
\text { Information Systems }\end{array}$ & $-0.698^{* * *}$ & $-0.522^{* *}$ & $2.160 * * *$ & -0.005 \\
\hline \multicolumn{5}{|l|}{ Control Variables } \\
\hline Hospital Size & -0.006 & -0.007 & -0.009 & -0.0001 \\
\hline $\mathrm{CMI}$ & $-2.409 * * *$ & $-0.832 * * *$ & 0.978 & -0.056 \\
\hline R-Square & 0.67 & 0.72 & 0.76 & 0.63 \\
\hline $\mathrm{F}$-Value & $32.28 * * *$ & $38.56 * * *$ & $24.40 * * *$ & $4.50 * * *$ \\
\hline $\mathrm{N}$ & 531 & 531 & 531 & 531 \\
\hline
\end{tabular}

First, we focus our analysis on IT Budget among the quality of care measures and financial indicator (ROI). From the results, we observe IT Budget has a positive relationship with Patient Satisfaction and Return on Investment, thus supporting Hypotheses 1.3 and 3. However, its relationship with Readmission Rates insignificant, and It is negatively correlated with mortality rates (coeff. $=31.98, \mathrm{p}<0.011$ ).

Next, we focus our analysis on the implementation of HIT systems on mortality and readmissions. Our results show that implementation of Clinical Information Systems (CIS) is associated with lower readmission rates (coeff. $=-1.423, \mathrm{p}<0.001$ ), thus supporting Hypothesis 2.1.2. Its relationship with mortality, however, is insignificant. Implementation of EMR systems is associated with lower readmissions rate (coeff. $=-0.819, \mathrm{p}<0.05)$ and lower mortality (coeff. $=-0.761, \mathrm{p}<0.001$ ), thus supporting both Hypothesis 2.2.1 and 2.2.2. Similarly, Implementation of Decision support systems is also associated with both lower mortality rates (coeff. $=-0.638, \mathrm{p}<0.001$ ) and lower readmission admission rates (coeff. = $0.057, \mathrm{p}<0.10$ ), thus supporting Hypotheses 2.3 .1 and 2.3.2. Implementation of Human Resource Information Systems is associated with lower mortality rates (coeff. $=-0.698, \mathrm{p}<0.001$ ) and lower readmission rates (coeff. $=-0.522, \mathrm{p}<00.5)$, thus supporting Hypothesis 2.4.1 and 2.4.2.

Our results show that implementation of Clinical Information Systems (coeff. $=1.627, \mathrm{p}<0.05$ ), Decision Support Systems (coeff. $=1.852, \mathrm{p}<0.001$ ), and Human Resource Systems (coeff. $=2.160, \mathrm{p}<0.05$ ) have positive impact on patient satisfaction, thus supporting Hypotheses 2.1.3, 2.3.3, and 2.4.2. Implementation of EMR however does not significantly improve patient satisfaction. Among these systems, only implementation of Clinical Information Systems is positively correlated with Return on Investment $(\mathrm{ROI}) \quad$ (coeff. $=0.005, \mathrm{p}<0.05)$. Implementations of Human resource information systems, Decision Support systems, and EMR systems do not appear to have a significant impact on ROI.

Our results also show that, one of the control variables, Case Mix Index, is significantly correlated with mortality and readmission rates, but not with patient satisfaction and ROI. The other control variable, hospital size is not significantly related with any of the independent variables.

\section{Conclusions and Limitations}

In this study, we aimed to find the relationship between HIT investments and Hospital Performance. Unlike previous studies, we use both IT Budget and implementations of HIT systems as indicators of hospital IT investments. We also conceptualize hospital performance as multidimensional that includes both the financial outcome, Return on Investment, and non-financial outcomes such as mortality, readmission rates, and patient satisfaction.

Our regression results based on a panel of U.S hospitals followed over a four-year time span from 2012 to 2015 demonstrate critical contrasts in the relationship between HIT investments and hospital quality of care and return on investment. On one hand, IT budget is associated with significant improvements in quality of care measures including mortality and patient satisfaction. Implementations of DSS, EMR, CIS and HRS also have positive impacts on the quality of care measures. On other hand, IT budget significantly impacts Return on Investment, while among the HIT systems, only CIS is positively related with ROI.

Our research shows that the overall IT budget and the implementations of different HIT systems provide significant value in improving hospital quality outcomes like mortality, readmissions, and patient satisfaction, but the impact of investment on new HIT systems on ROI is questionable and needs further investigation. 
Our research does have some limitations. First, we are restricted to a small dataset since only not all hospitals in the HIMSS dataset have reported their overall IT budget. Second, we use $1 \mathrm{~s}$ and $0 \mathrm{~s}$ to represent if a specific type of HIT technology is implemented or not. These binary numbers may not capture the actual degree of usage of these systems, which provides an interesting gap for future research. Greater details about HIT system implementation such as vendors, degree of inter-operability, and implementation methodologies could lead to research relevant to the field of HIT research. Third is that we did not account for lags in performance outcomes. The HIT investments may not have an immediate effect on hospital performance. If that is the case, the use of different models that can capture the lag effects is necessary.

\section{References}

[1] Agha, L., "The effects of health information technology on the costs and quality of medical care", Journal of Health Economics 34, 2014, pp. 19-30.

[2] Amarasingham, R., L. Plantinga, M. Diener-West, D.J. Gaskin, and N.R. Powe, "Clinical information technologies and inpatient outcomes: a multiple hospital study", Archives of Internal Medicine 169(2), 2009, pp. 108-114.

[3] Appari, A., E.K. Carian, M.E. Johnson, and D.L. Anthony, "Medication administration quality and health information technology: a national study of US hospitals", Journal of the American Medical Informatics Association 19(3), 2012, pp. 360-367.

[4] Bardhan, I.R., and M.F. Thouin, "Health information technology and its impact on the quality and cost of healthcare delivery", Decision Support Systems 55(2), 2013, pp. 438-449.

[5] Bates, D.W., "The quality case for information technology in healthcare", BMC Medical Informatics \& Decision Making 2(1), 2002, pp. 7-9.

[6] Bélanger, E., G. Bartlett, M. Dawes, C. Rodríguez, and I. Hasson-Gidoni, "Examining the evidence of the impact of health information technology in primary care: an argument for participatory research with health professionals and patients", International Journal of Medical Informatics 81(10), 2012, pp. 654-661.

[7] Botta-Genoulaz, V., and P.-A. Millet, "An investigation into the use of ERP systems in the service sector", International Journal of Production Economics 99(1), 2006, pp. 202-221.

[8] Burkhardt, J., and J. R C Wheeler, "Examining financial performance indicators for acute care hospitals", Journal of health care finance 39, 2013, pp. 1-13.

[9] Chaudhry, B., J. Wang, S. Wu, et al., "Systematic review: impact of health information technology on quality, efficiency, and costs of medical care", Annals of Internal Medicine 144(10), 2006, pp. 742-752.

[10] Cooper, R.B., and R.W. Zmud, "Information Technology Implementation Research: A Technological
Diffusion Approach", Management Science 36(2), 1990, pp. 123-139.

[11] Das, S.R., U. Yaylacicegi, and N.M. Menon, "The Effect of Information Technology Investments in Healthcare: A Longitudinal Study of its Lag, Duration, and Economic Value", IEEE Transactions on Engineering Management 58, 2011, pp. 124-140.

[12] DesRoches, C.M., E.G. Campbell, C. Vogeli, et al., "Electronic health records' limited successes suggest more targeted uses", Health Affairs (Project Hope) 29(4), 2010, pp. 639-646.

[13] Devaraj, S., and R. Kohli, "Information Technology Payoff in the Health-Care Industry: A Longitudinal Study", Journal of Management Information Systems 16(4), 2000, pp. 41-67.

[14] Devaraj, S., and R. Kohli, "Performance Impacts of Information Technology: Is Actual Usage the Missing Link?", Management Science 49(3), 2003, pp. 273-289.

[15] Dexter, P.R., S.M. Perkins, K.S. Maharry, K. Jones, and C.J. McDonald, "Inpatient computer-based standing orders vs physician reminders to increase influenza and pneumococcal vaccination rates: a randomized trial", JAMA 292(19), 2004, pp. 2366-2371.

[16] Doebbeling, B.N., A.F. Chou, and W.M. Tierney, "Priorities and Strategies for the Implementation of Integrated Informatics and Communications Technology to Improve Evidence-Based Practice", Journal of General Internal Medicine 21(Suppl 2), 2006, pp. S50-S57.

[17] Foster, D., C. Mcgregor, and S. El-masri, "A Survey of Agent-Based Intelligent Decision Support Systems to Support Clinical", Management and Research", 1st Intl. Workshop on Multi-Agent Systems for Medicine, Computational Biology, and Bioinformatics, (2004).

[18] Harb, Y., S. Sarnikar, and C. Noteboom, "An Exploration of the Impact of EMR Capabilities on Hospital Quality Measures in U. S.”, 2016 49th Hawaii International Conference on System Sciences (HICSS), (2016), 3162-3171. [19] Hashi, E.K., M.S.U. Zaman, and M.R. Hasan, "An expert clinical decision support system to predict disease using classification techniques", 2017 International Conference on Electrical, Computer and Communication Engineering (ECCE), (2017), 396-400.

[20] Himmelstein, D.U., A. Wright, and S. Woolhandler, "Hospital Computing and the Costs and Quality of Care: A National Study", The American Journal of Medicine 123(1), 2010, pp. 40-46.

[21] HIMSS, "Hospital IT Budgets as Percent of Total Operating Expense - Data360", data360.org, 2015. [Online]. Available:

www.data360.org/graph_group.aspx?Graph_Group_Id=1117 . [Accessed:04-Sep-2019].

[22] IBM, "Data-driven healthcare organizations use big data analytics for big", IBM Big Data \& Analytics Hub, 2013. [Online].

Available: https://www.ibmbigdatahub.com/whitepaper/data-drivenhealthcare-organizations-use-big-data-analytics-big-gains. [Accessed: 04-Sep-2019].

[23] Jyoti, S., A. Ujma, S. Dipesh, and S.B. Sunita, "Predictive Data Mining for Medical Diagnosis: An Overview of Heart Disease Prediction", (2011). 
[24] Kohli, R., and S. Devaraj, "Contribution of institutional DSS to organizational performance: evidence from a longitudinal study", Decision Support Systems 37(1), 2004, pp. 103-118.

[25] Ledwich, L.J., T.M. Harrington, W.T. Ayoub, J.A. Sartorius, and E.D. Newman, "Improved influenza and pneumococcal vaccination in rheumatology patients taking immunosuppressants using an electronic health record best practice alert", Arthritis and Rheumatism 61(11), 2009, pp. 1505-1510.

[26] Linder, J.A., J. Ma, D.W. Bates, B. Middleton, and R.S. Stafford, "Electronic health record use and the quality of ambulatory care in the United States", Archives of Internal Medicine 167(13), 2007, pp. 1400-1405.

[27] Mackel, J.V., H. Farris, B.S. Mittman, M. Wilkes, and D.E. Kanouse, "A Windows-based tool for the study of clinical decision-making”, Medinfo. MEDINFO 8 Pt 2, 1995, pp. 1687.

[28] Manyika, J., M. Chui, J. Buhin, R. Dobbs, C. Roxburgh, and A. Byers, "Big data: The next frontier for innovation,Competition, and Productivity", 2011.

[29] McCullough, J.S., M. Casey, I. Moscovice, and S. Prasad, "The Effect Of Health Information Technology On Quality In U.S. Hospitals", Health Affairs 29(4), 2010, pp. 647-654.

[30] Menon, N.M., B. Lee, and L. Eldenburg, "Productivity of Information Systems in the Healthcare Industry", Information Systems Research 11(1), 2000, pp. 83-92.

[31] Miller, R.H., C. West, T.M. Brown, I. Sim, and C. Ganchoff, "The Value of Electronic Health Records In Solo Or Small Group Practices", Health Affairs 24(5), 2005, pp. 1127-1137.

[32] Payne, T.H., D.W. Bates, E.S. Berner, et al., "Healthcare information technology and economics", Journal of the American Medical Informatics Association: JAMIA 20(2), 2013, pp. 212-217.

[33] Rajagopal, N., "Impact of Information Technology on Service Quality of Health Care Services.", XIMB Journal of Management 10(1), 2013, pp. 79-96.

[34] Rodin, S.-C.E., "Using Electronic Health Records to Improve Quality and Efficiency: The Experiences of Leading Hospitals", 2012, pp. 40.

[35] Romano, M.J., and R.S. Stafford, "Electronic health records and clinical decision support systems: impact on national ambulatory care quality", Archives of Internal Medicine 171(10), 2011, pp. 897-903.

[36] Srinivas, K., B.K. Rani, and D.A. Govrdhan, "Applications of Data Mining Techniques in Healthcare and Prediction of Heart Attacks", 02(02), 2010, pp. 7.

[37] Vermeeren, B., B. Steijn, L. Tummers, M. Lankhaar, R.J. Poerstamper, and S. van Beek, "HRM and its effect on employee, organizational and financial outcomes in health care organizations", Human Resources for Health 12, 2014, pp. 35.

[38] "Fewer Physicians See EHRs Improving Quality of Care", Medscape, 14-Apr-2015. [Online]. Available: http://www.medscape.com/viewarticle/843156. [Accessed: 05-Sep-2019].

[39] "WHO | What is Quality of Care and why is it important?", World Health Organization, 16-Feb-2017. [Online]. http://www.who.int/maternal_child_adolescent/topics/quality -of-care/definition/en/. [Accessed: 04-Sep-2019].

[40] "Health IT Spending Rises for Patient Satisfaction, Big Data", H\&HN. [Online]. Available: https://www.hhnmag.com/articles/7956-health-it-spendingrises-for-patient-satisfaction-big-data. [Accessed: 04-Sep2019].

\section{Appendix A}

\section{Appendix A. HIT System applications}

\begin{tabular}{|l|l|}
\hline HIT system & Applications \\
\hline EMR Systems & Clinical Data Repository \\
& Computerized Practitioner Order \\
& Entry (CPOE) \\
& Patient Portal \\
& Physician Portal \\
\hline $\begin{array}{l}\text { Decision Support } \\
\text { Systems }\end{array}$ & Data Warehousing and Data \\
& Mining \\
& Executive Information Systems \\
& Budgeting Systems \\
& Business Intelligence \\
\hline Clinical Information & Oncology Information System \\
Systems & OR Scheduling \\
& Emergency Department \\
& Information System \\
\hline Human Resource & Payroll \\
Information & Personal Management \\
Systems & Benefits Administration \\
& Staff Scheduling \\
\hline
\end{tabular}

